\title{
Acid Sphingomyelinase Gene Knockout Ameliorates Hyperhomocysteinemic Glomerular Injury in Mice Lacking Cystathionine- $\beta$-Synthase
}

\author{
Krishna M. Boini, Min Xia, Justine M. Abais, Ming Xu, Cai-xia Li, Pin-Lan Li* \\ Department of Pharmacology and Toxicology, Medical College of Virginia Campus, Virginia Commonwealth University, Richmond, Virginia, United States of America
}

\begin{abstract}
Acid sphingomyelinase (ASM) has been implicated in the development of hyperhomocysteinemia (hHcys)-induced glomerular oxidative stress and injury. However, it remains unknown whether genetically engineering of ASM gene produces beneficial or detrimental action on hHcys-induced glomerular injury. The present study generated and characterized the mice lacking cystathionine $\beta$-synthase (Cbs) and Asm mouse gene by cross breeding $\mathrm{Cbs}^{+/-}$and Asm ${ }^{+/-}$ mice. Given that the homozygotes of $\mathrm{Cbs}^{-/-} \mathrm{Asm}^{-1-}$ mice could not survive for 3 weeks. $\mathrm{Cbs}^{+/-1} \mathrm{Asm}^{+/}, \mathrm{Cbs}^{+/-} \mathrm{Asm}^{+/}$ and $\mathrm{Cbs}^{+/-} \mathrm{Asm}^{-/-}$as well as their Cbs wild type littermates were used to study the role of Asm ${ }^{-/-}$under a background of $\mathrm{Cbs}^{+/-}$with hHcys. HPLC analysis revealed that plasma Hcys level was significantly elevated in $\mathrm{Cbs}$ heterozygous $\left(\mathrm{Cbs}^{+/-}\right)$ mice with different copies of Asm gene compared to $\mathrm{Cbs}^{+/+}$mice with different Asm gene copies. $\mathrm{Cbs}^{+/-} \mathrm{Asm}^{+/+} \mathrm{mice} \mathrm{had}^{+1 /+}$ significantly increased renal Asm activity, ceramide production and $\mathrm{O}_{2}{ }^{-}$. level compared to $\mathrm{Cbs}^{+/+} / \mathrm{Asm}^{+/+}$, while $\mathrm{Cbs}^{+/}$

${ }^{-} \mathrm{Asm}^{-1-}$ mice showed significantly reduced renal Asm activity, ceramide production and $\mathrm{O}_{2}$. ${ }^{-}$level due to increased plasma Hcys levels. Confocal microscopy demonstrated that colocalization of podocin with ceramide was much lower in $\mathrm{Cbs}^{+/-} \mathrm{Asm}^{-/-}$mice compared to $\mathrm{Cbs}^{+/-} \mathrm{Asm}^{+/+}$mice, which was accompanied by a reduced glomerular damage index, albuminuria and proteinuria in $\mathrm{Cbs}^{+/-} \mathrm{Asm}^{-/-}$mice. Immunofluorescent analyses of the podocin, nephrin and desmin expression also illustrated less podocyte damages in the glomeruli from $\mathrm{Cbs}^{+/-1} \mathrm{Asm}^{-/-}$mice compared to $\mathrm{Cbs}^{+/-/} \mathrm{Asm}^{+/+}$ mice. In in vitro studies of podocytes, hHcys-enhanced $\mathrm{O}_{2}{ }^{-}$production, desmin expression, and ceramide production as well as decreases in VEGF level and podocin expression in podocytes were substantially attenuated by prior treatment with amitriptyline, an Asm inhibitor. In conclusion, Asm gene knockout or corresponding enzyme inhibition protects the podocytes and glomeruli from hHcys-induced oxidative stress and injury.
\end{abstract}

Citation: Boini KM, Xia M, Abais JM, Xu M, Li C-x, et al. (2012) Acid Sphingomyelinase Gene Knockout Ameliorates Hyperhomocysteinemic Glomerular Injury in Mice Lacking Cystathionine- $\beta$-Synthase. PLoS ONE 7(9): e45020. doi:10.1371/journal.pone.0045020

Editor: Christos Chatziantoniou, Institut National de la Santé et de la Recherche Médicale, France

Received March 13, 2012; Accepted August 16, 2012; Published September 14, 2012

Copyright: (c) 2012 Boini et al. This is an open-access article distributed under the terms of the Creative Commons Attribution License, which permits unrestricted use, distribution, and reproduction in any medium, provided the original author and source are credited.

Funding: This work was supported by grants DK54927, HL091464, HL57244 and HL075316 from the National Institutes of Health. The funder had no role in study design, data collection and analysis, decision to publish, or preparation of the manuscript.

Competing Interests: The authors have declared that no competing interests exist.

*E-mail: pli@vcu.edu

\section{Introduction}

Acid sphingomyelinase (ASM), a ceramide producing enzyme has been reported to be involved in the regulation of cell and organ functions and has been implicated in the development of different diseases such as obesity, diabetes, atherosclerosis, kidney diseases and disorder of lipid metabolism [1-3]. ASM hydrolyzes sphingomyelin to ceramide and phosphorylcholine and thereby exerts its signaling or regulatory role. It has been reported that ASM deficiency leads to Niemann-Pick disease in humans and that Asm gene (Asm is commonly used to represent mouse gene for ASM) knockout in mice resulted in the resistance to radiation [4] and other forms of stress-induced apoptosis [1]. Similarly, inhibition of ASM activity has also been shown to render cells and animals resistant to the apoptotic effects of diverse stimuli including Fas/CD95 [5], ischemia [6], radiation [7], chemotherapy [8] tumor necrosis factor-alpha (TNF- $\alpha$ ) [9]. In addition, Asm knockout or Asm inhibition was shown to have protective action during the lung inflammation and fibrosis [10], cystic fibrosis [1112], obesity and associated glomerular injury [13], liver fibrogenesis [14] and renal fibrosis [15].
In recent studies, we and others have demonstrated that ASM can be activated during hHcys whereby ceramide is produced to result in activation of NADPH oxidase, local oxidative stress and consequent glomerulosclerosis and loss of kidney functions [1619]. However, most of these studies were done using pharmacological or molecular interventions, but to our knowledge no genetic approaches have been used to address the role of ASMceramide regulatory mechanism in the development of hHcysassociated glomerular injury or end-stage renal disease. Recently, the characterization of Cbs gene knockout mice as one of the hHcys model and development of Asm gene deletion in mice [2021] provide opportunity to address whether genetically manipulation of both genes can alter hHcys-induced pathological changes, in particular in the renal glomeruli, which is a major focus of our laboratory. In the present study, we hypothesized that genetically engineering of Asm gene protects glomeruli from hHcys-induced glomerular oxidative stress and thereby ameliorate podocyte injury and glomerulosclerosis during hHcys. To test this hypothesis, we for the first time generated the mice lacking Asm and Cbs gene (lacking one alle of Cbs and two alle of Asm genes) to determine whether Asm deletion has any affect on glomerular oxidative stress 
and podocyte injury by hHcys that is occurred in Cbs gene deficient mice. By analysis of Asm homozygous and heterozygous mice with a background of Cbs partially deletion, we tried to obtain gene titration data clarifying the pathogenic role in hHcys. Using culture murine podocytes, we further examined the direct effects of ASM inhibition on Hcys-induced cellular oxidative stress and related injury. These in vivo and in vitro experiments elucidate the role of ASM in the development of podocyte injury and glomerular sclerosis associated with hHcys, which may identify an important target for possible gene therapy during the course of hHcys-induced pathology.

\section{Results}

\section{Genotyping and Plasma Hcys Concentrations in DKO Mice}

The genotypes of the mutant mice were confirmed by PCR using Cbs and Asm mouse gene specific primers. As shown in Figure 1B, when Cbs gene primer was used for genotyping, a $321 \mathrm{bp}$ and $1500 \mathrm{bp}$ product could be detected. Mice with only a $321 \mathrm{bp}$ band are wild type $\left(\mathrm{Cbs}^{+/+}\right)$, while mice with two bands are heterozygotes $\left(\mathrm{Cbs}^{+-}\right)$. In Asm genotyping, mice showing a single product of 269 or $523 \mathrm{bp}$ indicate Asm wild type $\left(\mathrm{Asm}^{+/+}\right)$ and homozygotes $\left(\mathrm{Asm}^{-1-}\right)$, respectively. If both the two products was detected in the same mice, these mice were heterozygotes of Asm gene $\left(\mathrm{Asm}^{+/-}\right)$. HPLC analyses showed that the plasma Hcys concentrations was similar among $\mathrm{Cbs}^{+/+} / \mathrm{Asm}^{+/+}, \mathrm{Cbs}^{+/+} / \mathrm{Asm}^{+/}$ and $\mathrm{Cbs}^{+/+} / \mathrm{Asm}^{-/-}$mice, which showed different Asm gene types with the same background of Cbs wild type. Compared to these Cbs wild type mice, the plasma Hcys concentrations were significantly increased in Cbs heterozygotes with different Asm gene copies, namely, $\mathrm{Cbs}^{+/-} \mathrm{Asm}^{+/+}, \mathrm{Cbs}^{+/-} \mathrm{Asm}^{+/-}$and $\mathrm{Cbs}^{+/}$

${ }^{-} \mathrm{Asm}^{-/-}$mice, but there was no significant difference in plasma Hcys levels in this group of mice with $\mathrm{Cbs}^{+/-}$background with different copies of Asm gene (Figure 1C). These data suggest that Asm gene is not involved in the regulation of plasma Hcys levels and therefore it does not alter the occurrence of hHcys in mice.

As illustrated in Figure 2A, the total renal ceramide levels were substantially lower in $\mathrm{Cbs}^{+/+} / \mathrm{Asm}^{-/-}$than $\mathrm{Cbs}^{+/+} / \mathrm{Asm}^{+/+}$and $\mathrm{Cbs}^{+/+} / \mathrm{Asm}^{+/-}$mice. However, increased plasma Hcys level was accompanied by significantly increased renal ceramide levels in $\mathrm{Cbs}^{+/-} \mathrm{Asm}^{+/+}$mice, but not in $\mathrm{Cbs}^{+/-} \mathrm{Asm}^{-/-}$mice. Furthermore, confocal microscopic studies revealed that ceramide staining was more pronounced in glomeruli of $\mathrm{Cbs}^{+/-/} \mathrm{Asm}^{+/+}$mice than in $\mathrm{Cbs}^{+/-} \mathrm{Asm}^{-1-}$ mice (Figure 2B). In addition, using podocin as a podocyte marker we showed that hHcys-induced ceramide expression in glomeruli were mostly located in podocytes, as demonstrated by the colocalization of ceramide with podocin. This colocalization was substantially blocked in $\mathrm{Cbs}^{+/-} \mathrm{Asm}^{-/-}$mice (Figure 2B). The Asm activity was significantly lower in $\mathrm{Cbs}^{+++}$/ $\mathrm{Asm}^{-/-}$compared to $\mathrm{Cbs}^{+/+} / \mathrm{Asm}^{+/+}$mice, but it was significantly increased in $\mathrm{Cbs}^{+/-} \mathrm{Asm}^{+/+}$compared to $\mathrm{Cbs}^{+/+} / \mathrm{Asm}^{+/+}$ mice. However, this hHcys-induced Asm activity was significantly attenuated in $\mathrm{Cbs}^{+/-} \mathrm{Asm}^{-/-}$mice (Figure 2C).

\section{Attenuation of hHcys-induced Glomerular Injury in $\mathrm{Cbs}^{+/}$ - by Further Knockout of Asm Gene}

As depicted in Figure 3A and 3B, urinary protein and albumin excretion was similar in $\mathrm{Cbs}^{+/+} / \mathrm{Asm}^{+/+}, \mathrm{Cbs}^{+/+} / \mathrm{Asm}^{+/-}$and $\mathrm{Cbs}^{+/+} / \mathrm{Asm}^{-/-}$mice. However, the urinary total protein and albumin excretion increased significantly in $\mathrm{Cbs}^{+/-/} \mathrm{Asm}^{+/+}$mice, but not in $\mathrm{Cbs}^{+/-} \mathrm{Asm}^{-/-}$mice, despite that both mouse strains have hHcys. By PAS staining, we observed a typical pathological change showing glomerular sclerotic damage in $\mathrm{Cbs}^{+/-} \mathrm{Asm}^{+/+}$
A

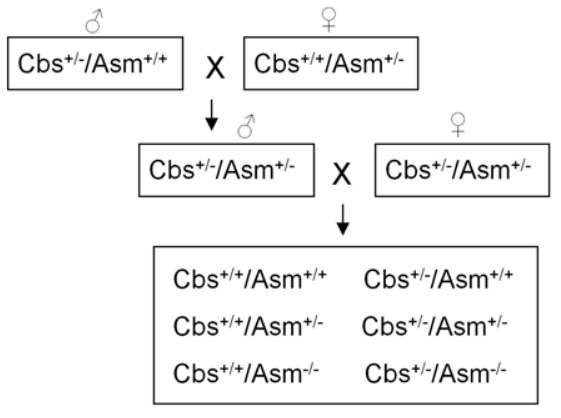

B

C
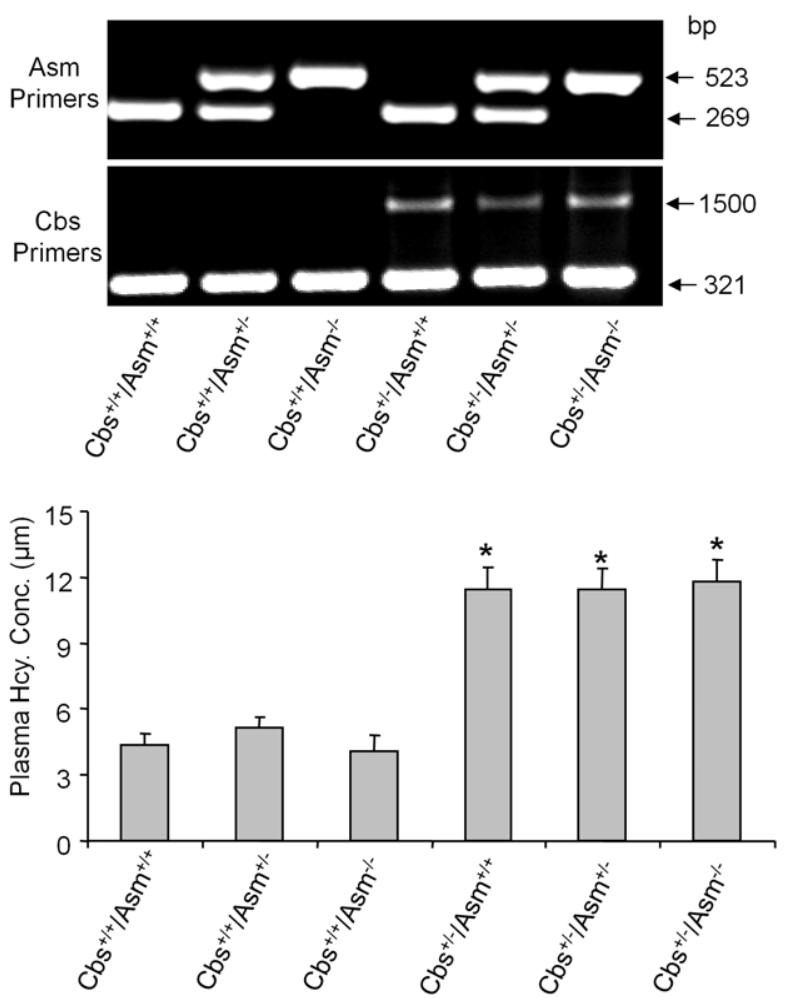

Figure 1. Genotyping and Plasma Hcys concentrations in $\mathrm{Cbs}^{+1}$ ${ }^{+} / \mathrm{Asm}^{+/+}, \mathrm{Cbs}^{+/+} / \mathrm{Asm}^{+/-}, \mathrm{Cbs}^{+/} / \mathrm{Asm}^{-1-}, \mathrm{Cbs}^{+1-l} \mathrm{Asm}^{+/+}, \mathrm{Cbs}^{+1}$ ${ }^{-1} \mathbf{A s m}^{+\prime-}$ and $\mathbf{C b s}^{+I-1} \mathbf{A s m}^{-I-}$ mice. A: Breeding scheme used to generate $\mathrm{Cbs}^{+/+} / \mathrm{Asm}^{+/+}, \mathrm{Cbs}^{+/+} / \mathrm{Asm}^{+/-}, \mathrm{Cbs}^{+/+} / \mathrm{Asm}^{-/-}, \mathrm{Cbs}^{+/-} \mathrm{Asm}^{+/+}$, $\mathrm{Cbs}^{+-1} \mathrm{Asm}^{+/-}$and $\mathrm{Cbs}^{+/-} \mathrm{Asm}^{-/-}$mice. B: Genotyping in mutant mice. Two PCR products suggest that heterozygous mutation, while single band represents wild type or knockout allele. C: Values are arithmetic means $\pm S E(n=6$ each group) of plasma Hcys concentrations in $\mathrm{Cbs}^{++} / \mathrm{Asm}^{+/+}, \mathrm{Cbs}^{+/+} / \mathrm{Asm}^{+/-}, \mathrm{Cbs}^{+/+} / \mathrm{Asm}^{-/-}, \mathrm{Cbs}^{+/-} \mathrm{Asm}^{+/}$, $\mathrm{Cbs}^{+/-} \mathrm{Asm}^{+/-}$and $\mathrm{Cbs}^{+/-} \mathrm{Asm}^{-1-}$ mice. ${ }^{*}$ Significant difference $(P<0.05)$ compared to the values from $\mathrm{Cbs}^{+/+} / \mathrm{Asm}^{+/+}$mice; ${ }^{\#}$ Significant difference $(P<0.05)$ compared to the values from $\mathrm{Cbs}^{+/-} \mathrm{Asm}^{+/+}$mice. doi:10.1371/journal.pone.0045020.g001

mice such as glomerular capillary collapse and mesangial expansion. This pathology was not observed in $\mathrm{Cbs}^{+/-} \mathrm{Asm}^{-/-}$ mice. The average glomerular damage index (GDI) was significantly higher in $\mathrm{Cbs}^{+/-} \mathrm{Asm}^{+/+}$mice than in $\mathrm{Cbs}^{+/-} \mathrm{Asm}^{-/-}$ mice (Figure $3 \mathrm{C}$ and $3 \mathrm{D}$ ).

Further, we determined whether protective effect of $\mathrm{Cbs}^{+/}$ ${ }^{-/} \mathrm{Asm}^{-/-}$gene knockout is associated with the protection of podocytes in hHcys-induced glomerular injury. As shown in Figure $4 \mathrm{~A}$, the immunofluorescent analysis showed that desmin staining was more pronounced in glomeruli of $\mathrm{Cbs}^{+/-} \mathrm{Asm}^{+/+}$ than $\mathrm{Cbs}^{+/+} / \mathrm{Asm}^{+/+}$and $\mathrm{Cbs}^{+/+} / \mathrm{Asm}^{+/-}$mice, as shown by 
A

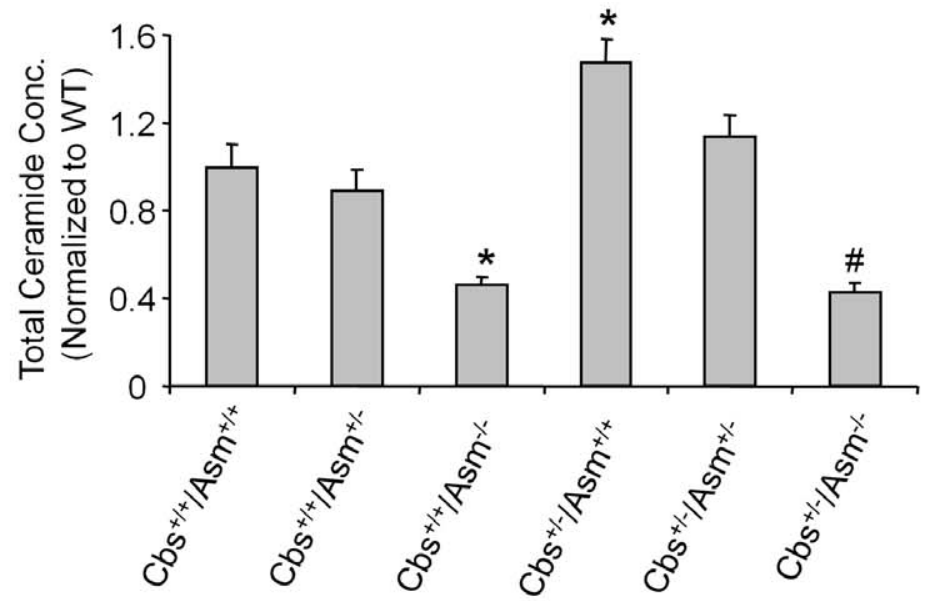

B

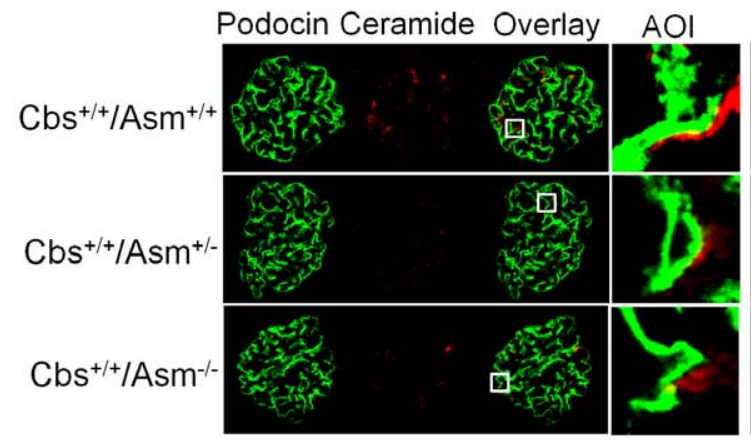

Podocin Ceramide Overlay

$\mathrm{AOI}$
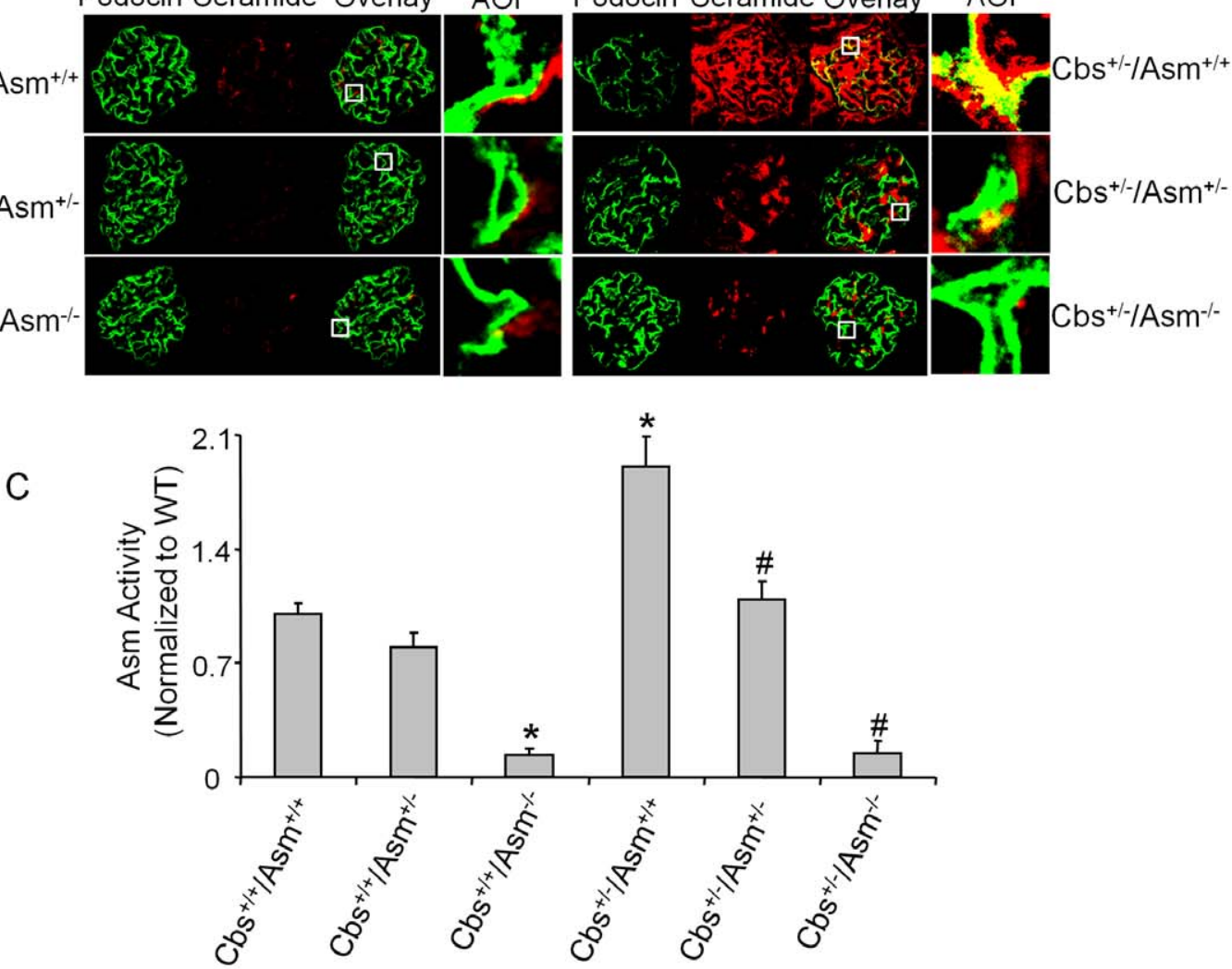

Figure 2. Renal tissue ceramide production and Asm activity in $\mathrm{Cbs}^{+/+} / \mathrm{Asm}^{+/+}, \mathrm{Cbs}^{+/+} / \mathrm{Asm}^{+/-}, \mathrm{Cbs}^{+/+} / \mathrm{Asm}^{-/-}, \mathrm{Cbs}^{+/-} \mathrm{Asm}^{+/+}, \mathrm{Cbs}^{+/}$ ${ }_{-1}^{-} \mathbf{A s m}^{+/-}$and $\mathbf{C b s}^{+1-} \mathbf{A s m}^{-1-}$ mice. Values are arithmetic means $\pm \mathrm{SE}(\mathrm{n}=6$ each group) of total ceramide concentrations (A), ceramide production (B) and Asm activity (C) in $\mathrm{Cbs}^{+/} / \mathrm{Asm}^{+/+}, \mathrm{Cbs}^{+/} / \mathrm{Asm}^{+/}, \mathrm{Cbs}^{+/+} / \mathrm{Asm}^{-/-}, \mathrm{Cbs}^{+/-} \mathrm{Asm}^{+/}, \mathrm{Cbs}^{+/-} \mathrm{Asm}^{+/-}$and $\mathrm{Cbs}^{+/-} \mathrm{Asm}^{-/-} \mathrm{mice}^{\mathrm{T}}$ The $\mathrm{AOI}$ shows the higher magnification of boxed area in overlaid images in panel $\mathrm{B}$. AOl: Area of interest. * Significant difference $(P<0.05)$ compared to the values from $\mathrm{Cbs}^{+/+} / \mathrm{Asm}^{+/+}$mice; \# Significant difference $(P<0.05)$ compared to the values from $\mathrm{Cbs}^{+/-} \mathrm{Asm}^{+/+}$mice. doi:10.1371/journal.pone.0045020.g002

more remarkable red fluorescence detected in glomeruli, which indicates podocytes injury. However in $\mathrm{Cbs}^{+/-} \mathrm{Asm}^{-/-}$mice the hHcys-induced increase in desmin expression within glomeruli of mice was not observed (Figure 4A). In contrast, other podocyte markers podocin and nephrin staining were found markedly reduced in glomeruli of $\mathrm{Cbs}^{+/-} \mathrm{Asm}^{+/+}$mice compared to $\mathrm{Cbs}^{+/}$ ${ }^{+} / \mathrm{Asm}^{+/+}$and $\mathrm{Cbs}^{+/+} / \mathrm{Asm}^{+/-}$mice, and in $\mathrm{Cbs}^{+/-} \mathrm{Asm}^{-/-}$ mice this reduced podocin and nephrin expression or production were not observed (Figure 4A). In addition, Western blot analysis demonstrated that desmin protein expression was significantly increased in $\mathrm{Cbs}^{+/-/} \mathrm{Asm}^{+/+}$mice compared to $\mathrm{Cbs}^{+/+} / \mathrm{Asm}^{+/+}$. However, the enhanced desmin expression was attenuated in $\mathrm{Cbs}^{+/-} \mathrm{Asm}^{-/-}$mice (Figure $4 \mathrm{~B}$ and $4 \mathrm{C}$ ).

Lack of Local Oxidative Stress in the Glomeruli of $\mathrm{Cbs}^{+/}$ ${ }^{-/} \mathrm{Asm}^{-/-}$Mice with hHcys

As illustrated in Figure 5A, the ESR spectrometric curve exhibited significant increase in the amplitude of Nox-dependent 
A

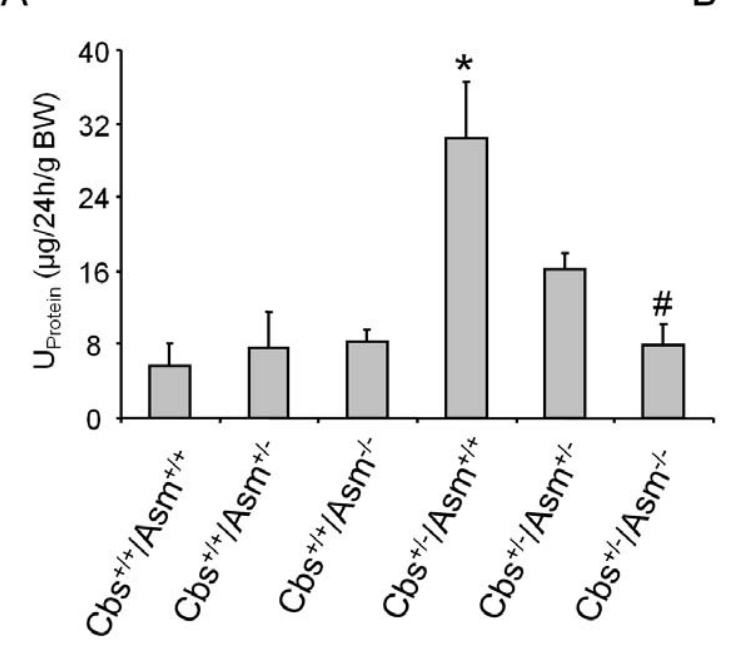

C

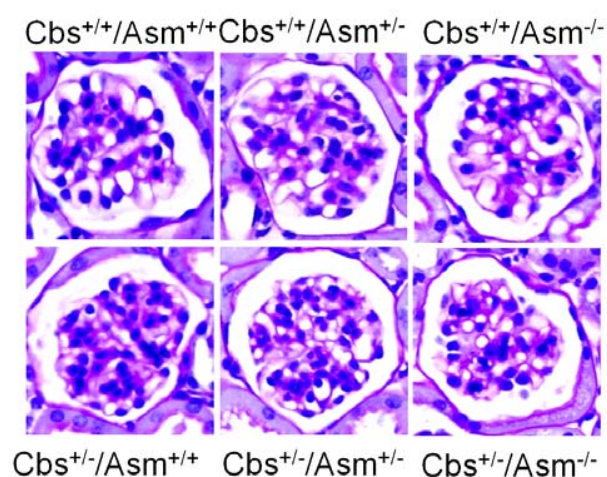

B

D
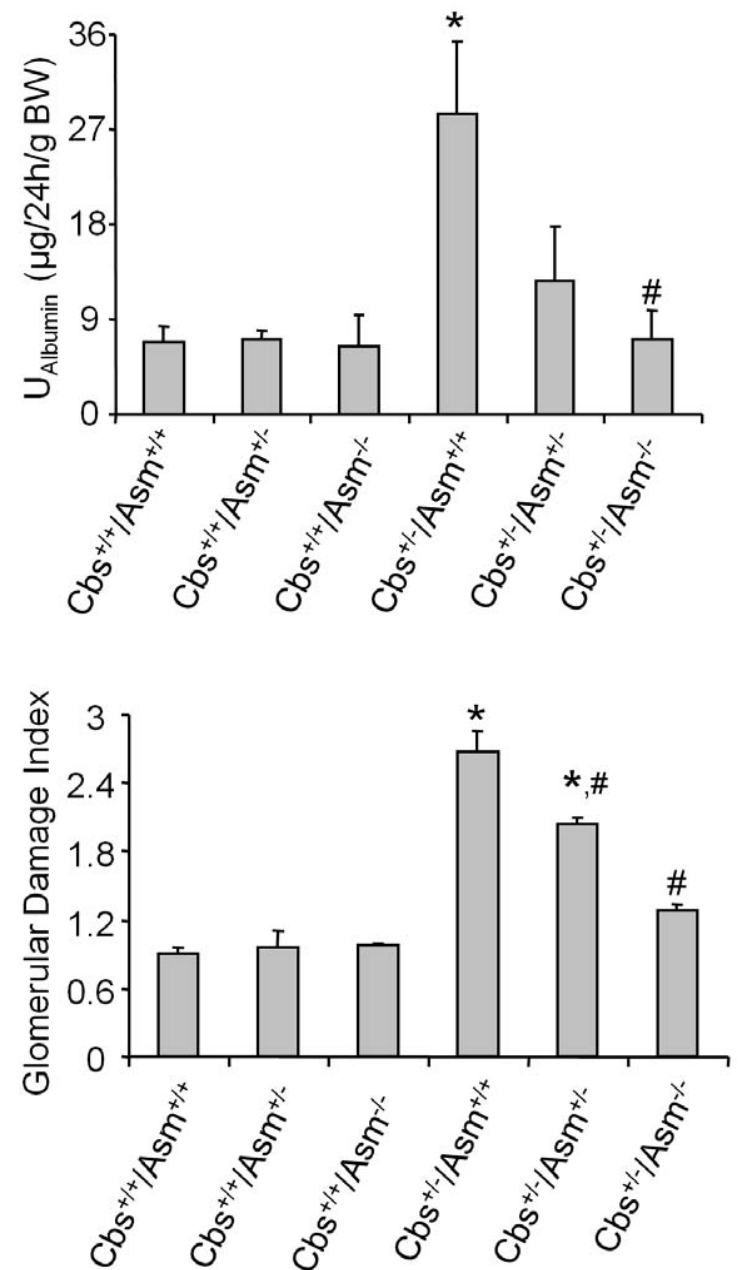

Figure 3. Glomerular injury in $\mathrm{Cbs}^{+/+} / \mathrm{Asm}^{+/+}, \mathrm{Cbs}^{+/+} / \mathrm{Asm}^{+/-}, \mathrm{Cbs}^{+/+} / \mathrm{Asm}^{-1-}, \mathrm{Cbs}^{+/-} \mathrm{Asm}^{+/+}, \mathrm{Cbs}^{+/-} \mathrm{Asm}^{+/-}$and $\mathrm{Cbs}^{+/-} \mathrm{Asm}^{-/-} \mathrm{mice}^{\mathrm{C}}$ A: Values are arithmetic means \pm SEM ( $n=6$ each group) of urinary total protein excretion, B: Urinary albumin excretion in $\mathrm{Cbs}^{+/+} / \mathrm{Asm}^{+/+}, \mathrm{Cbs}^{+/+} /$ $\mathrm{Asm}^{+/-}, \mathrm{Cbs}^{+/} / \mathrm{Asm}^{-/-}, \mathrm{Cbs}^{+/-} \mathrm{Asm}^{+/}, \mathrm{Cbs}^{+/-} \mathrm{Asm}^{+/}$and $\mathrm{Cbs}^{+-} \mathrm{Asm}^{-1-}$ mice. C: Photomicrographs show typical glomerular structure (original magnification, x400) in $\mathrm{Cbs}^{+/} / \mathrm{Asm}^{+/+}, \mathrm{Cbs}^{+/} / \mathrm{Asm}^{+/}, \mathrm{Cbs}^{+/} / \mathrm{Asm}^{-/-}, \mathrm{Cbs}^{+/-} \mathrm{Asm}^{+/+}, \mathrm{Cbs}^{+/-} \mathrm{Asm}^{+/-}$and $\mathrm{Cbs}^{+/-} \mathrm{Asm}^{-/-}$mice. D: Summarized data of glomerular damage index (GDI) by semi-quantitation of scores in 6 different groups of mice $(n=6$ each group). For each kidney section, 50 glomeruli were randomly chosen for the calculation of GDI. * Significant difference $(P<0.05)$ compared to the values from $\mathrm{Cbs}^{+/+} / \mathrm{Asm}^{+/+} \mathrm{mice}^{\#}$ Significant difference $(P<0.05)$ compared to the values from $\mathrm{Cbs}^{+/-1} \mathrm{Asm}^{+/+}$mice.

doi:10.1371/journal.pone.0045020.g003

ESR $\mathrm{O}_{2}{ }^{-}$signals in the glomeruli of $\mathrm{Cbs}^{+/-/} \mathrm{Asm}^{+/+}$mice compared to mice with $\mathrm{Cbs}^{+/+}$background and different copies of Asm genes. However, this enhanced glomerular $\mathrm{O}_{2}{ }^{-}$production in $\mathrm{Cbs}^{+/-} \mathrm{Asm}^{+/+}$mice was not observed in $\mathrm{Cbs}^{+/-} \mathrm{Asm}^{-/-}$ mice. These results were summarized in Figure $5 \mathrm{~B}$, showing that glomerular $\mathrm{O}_{2}{ }^{-}$production was similar in all $\mathrm{Cbs}^{+/+}$mice with different Asm gene copies, but it was increased by 3.1 folds in $\mathrm{Cbs}^{+/-} \mathrm{Asm}^{+/+}$mice compared to those mice with $\mathrm{Cbs}^{+/+}$and different Asm gene copies. This hHcys-induced glomerular $\mathrm{O}_{2}{ }^{-}$ level enhanced in $\mathrm{Cbs}^{+/-} \mathrm{Asm}^{+/+}$mice were attenuated in $\mathrm{Cbs}^{+/}$ ${ }^{-} \mathrm{Asm}^{-1-}$ mice.

\section{Blockade of Hcys-induced Ceramide Expression and}

Podocyte Injury by Asm Inhibition in Cultured Podocytes

The above studies demonstrated that mice lacking Cbs and Asm gene protect glomerular oxidative stress, injury and podocyte injury. We further performed some in vitro experiments to confirm whether glomerular injury truly occurs in podocytes. Using cultured murine podocytes, we examined ceramide production and related expression of podocyte markers. As shown in Figure 6, immunofluorescent analysis demonstrated that Hcys stimulation increased the desmin and ceramide expression in podocytes compared to untreated cells. Prior treatment with Asm inhibitor, amitriptyline decreased Hcys-induced elevation of desmin and ceramide production in podocytes (Figure 6A). Another podocyte marker, however, podocin was markedly reduced upon Hcys stimulation in podocytes, and the Asm inhibition almost completely attenuated the decrease in podocin expression (Figure 6A). The summarized data were shown in Figure 6B.

\section{Blockade of Hcys-induced Oxidative Stress and Decrease in VEGF-A Secretion by Asm Inhibition}

As depicted in Figure 7A, the $\mathrm{O}_{2}{ }^{-}$- production was similar in both control and amitriptyline-treated podocytes. However, the Hcys stimulation significantly increased the $\mathrm{O}_{2}$. 1.9 folds compared to control cells, but prior treatment with 


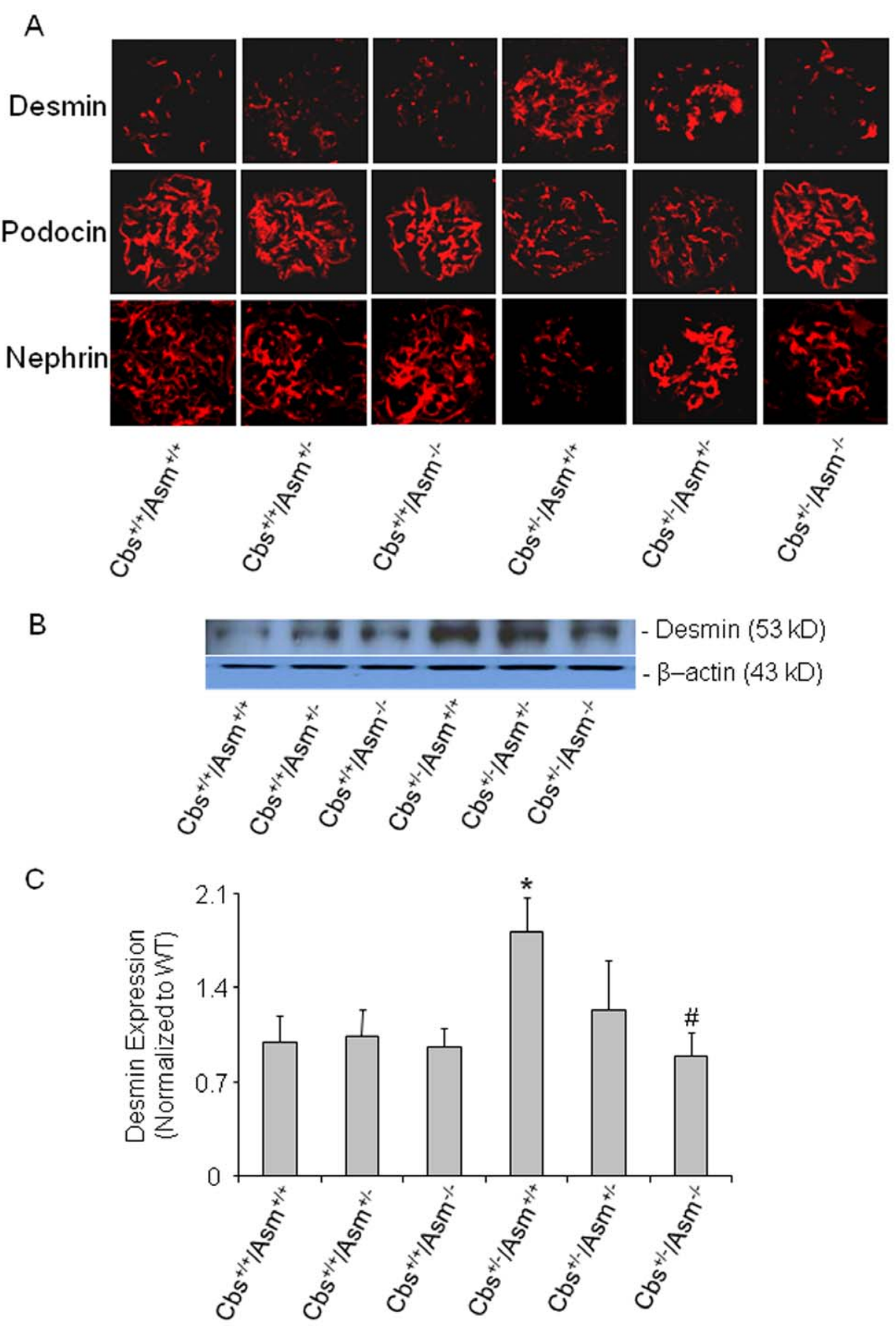

Figure 4. Immunofluorescent staining of anti-desmin, anti-podocin and anti-nephrin antibody in glomeruli of $\mathrm{Cbs}^{+/+} / \mathrm{Asm}^{+/+}, \mathrm{Cbs}^{+/+} \mathrm{I}$ $\mathbf{A s m}^{+l-}, \mathbf{C b s}^{+/} / \mathbf{A s m}^{-1-}, \mathbf{C b s}^{+/-} \mathbf{A s m}^{+/+}, \mathbf{C b s}^{+/-} \mathbf{A s m}^{+/-}$and $\mathbf{C b s}^{+/-} \mathbf{A s m}^{-1-}$ mice. A: Typical images of desmin, podocin and nephrin staining in glomeruli from $\mathrm{Cbs}^{+/+} / \mathrm{Asm}^{+/}, \mathrm{Cbs}^{+/+} / \mathrm{Asm}^{+/}, \mathrm{Cbs}^{+/} / \mathrm{Asm}^{-/-}, \mathrm{Cbs}^{+/-} \mathrm{Asm}^{+/+}, \mathrm{Cbs}^{+/-} \mathrm{Asm}^{+/-}$and $\mathrm{Cbs}^{+/-}$Asm ${ }^{-/-}$mice $(\mathrm{n}=6$ each group). B: Western blot analysis of desmin protein expression in different groups of mice. C: Summarized data showing the quantification of desmin expression, which was normalized to $\beta$-actin $(n=6)$. * Significant difference $(P<0.05)$ compared to the values from $\mathrm{Cbs}^{+/+} / \mathrm{Asm}^{+/+}$mice; $\#$ Significant difference $(P<0.05)$ compared to the values from $\mathrm{Cbs}^{+-1} \mathrm{Asm}^{+/+}$mice.

doi:10.1371/journal.pone.0045020.g004

amitriptyline significantly attenuated the Hcys-induced $\mathrm{O}_{2}$. production (Figure 7A). As a functional parameter of podocytes, VEGF-A production was detected in podocytes under various conditions. It was found that VEGF-A production and secretion were dramatically decreased by L-Hcys treatment compared to control cells. However, pretreatment of podocytes with amitriptyline significantly attenuated the Hcys-induced VEGF-A secre- tion. PAN is served a positive control (Figure 7B). Furthermore, we also performed the immunofluorescent experiments using rhodamine-phalloidin as a dye for F-actin, it was found that Hcys treatment induced dramatic reorganization and disruption of the F-actin cytoskeleton in podocytes compared to control cells. However, pretreatment of podocytes with amitriptyline attenuated 
A

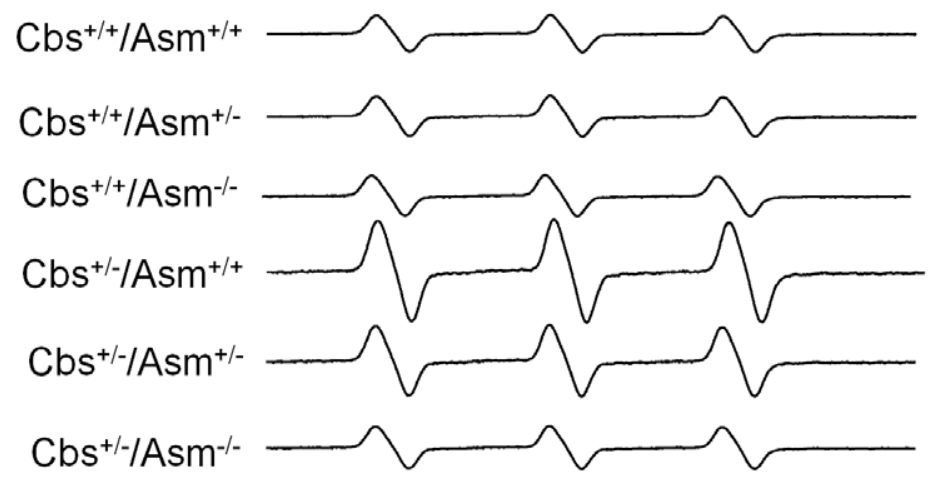

B

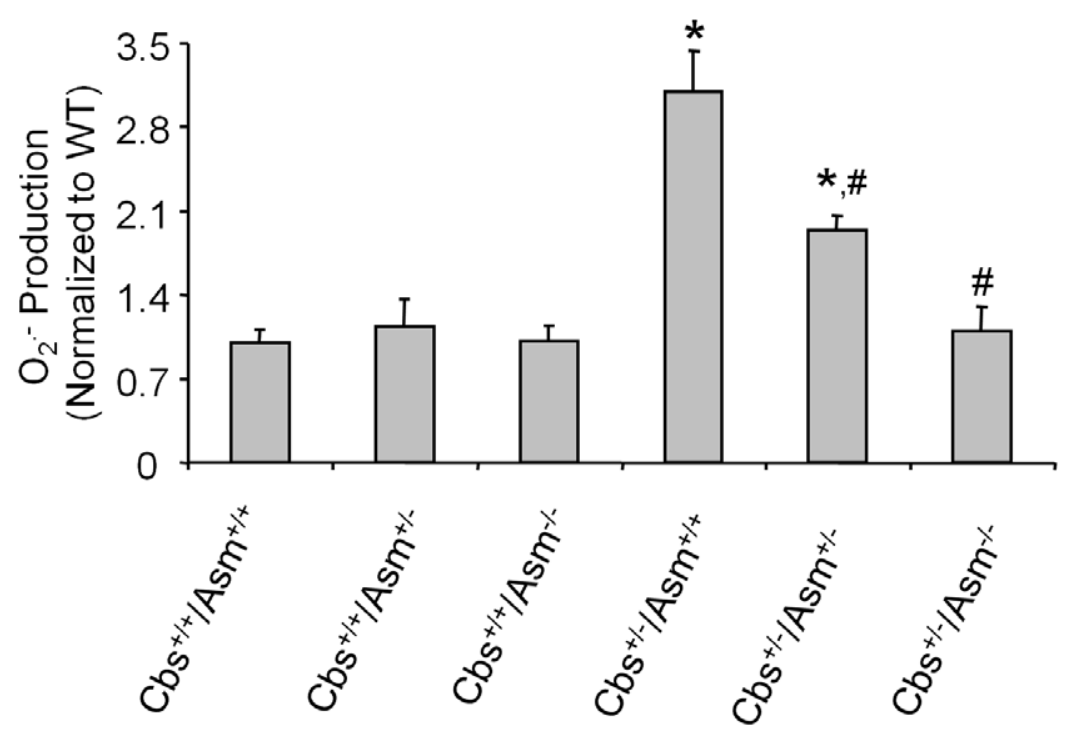

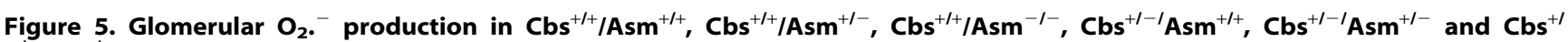
${ }^{-1} \mathbf{A s m}^{-1-}$ mice. A: Representative ESR spectra traces for $\mathrm{O}_{2}{ }^{-}$production in 6 different groups of mice. B: Values are arithmetic means \pm SEM $(\mathrm{n}=5$ each group) of $\mathrm{O}_{2} \cdot{ }_{-}^{-}$production in $\mathrm{Cbs}^{+/+} / \mathrm{Asm}^{+/+}, \mathrm{Cbs}^{+/} / \mathrm{Asm}^{+/-}, \mathrm{Cbs}^{+/} / \mathrm{Asm}^{-1-}, \mathrm{Cbs}^{+-} \mathrm{Asm}^{+/+}, \mathrm{Cbs}^{+/-} \mathrm{Asm}^{+/-}$and $\mathrm{Cbs}^{+/-} \mathrm{Asm}^{-/-}$. ${ }^{*} \mathrm{Significant}^{+1}$ difference $(P<0.05)$ compared to the values from $\mathrm{Cbs}^{+/+} / \mathrm{Asm}^{+/+}$mice; ${ }^{\#}$ Significant difference $(P<0.05)$ compared to the values from $\mathrm{Cbs}^{+/-} \mathrm{Asm}^{+/+}$ mice.

doi:10.1371/journal.pone.0045020.g005

the Hcys-induced disruption of F-actin cytoskeleton in podocytes and were restored to normal (Figure 7C and 7D).

\section{Discussion}

The major goal of the present study is to determine whether genetically engineering of acid sphingomyelinase (Asm) produces beneficial or detrimental effects in the development of hHcysinduced glomerular injury and sclerosis. We found that the genetic model of hyperhomocysteinemic $\mathrm{Cbs}$ mice $\left(\mathrm{Cbs}^{+/-/} \mathrm{Asm}^{+/+}\right)$ enhanced the ceramide production and Asm activity, which was attributed to NADPH oxidase dependent $\mathrm{O}_{2}$. local oxidative stress in glomeruli and ultimately led to podocyte injury and glomerulosclerosis. These results demonstrate for the first time that mice lacking $\mathrm{Cbs}$ and Asm gene $\left(\mathrm{Cbs}^{+/-} \mathrm{Asm}^{-/-}\right)$ protect against the hHcys-induced glomerular oxidative stress and injury in mice.

We first generated and characterized the mice lacking cystathionine $\beta$-synthase (Cbs) and acid sphingomyelinase (Asm) gene by cross breeding $\mathrm{Cbs}^{+/-}$and $\mathrm{Asm}^{+/-}$mice. Given that the homozygotes of $\mathrm{Cbs}^{-1-1} \mathrm{Asm}^{-/-}$mice could not survive for 3 weeks, $\mathrm{Cbs}^{+/-} \mathrm{Asm}^{+/+}, \mathrm{Cbs}^{+/-} \mathrm{Asm}^{+/-}$and $\mathrm{Cbs}^{+/-} \mathrm{Asm}^{-/-}$as well as their Cbs wild type littermates were used to study the role of $\mathrm{Asm}^{-1-}$ under a background of $\mathrm{Cbs}^{+/-}$that produced hHcys. Previous studies have shown that Hcys levels in the blood are a complex trait that is affected by several genetic and environmental factors. It is known that genetic factors contribute to mild, moderate [22] and severe hHcys [23], and that the genetic background is the specific collection of allelic gene variants that make individuals to present different inheritable characters within species. In this sense, inbred mouse strains are widely used to study the effects of different genetic background on the disease phenotype [24]. In the present study, we tested the role of Asm gene in the development of hHcys-induced glomerular injury or sclerosis by using $\mathrm{Cbs}^{+/-}$mutant mice. These mice have $50 \%$ reduction in Cbs mRNA and enzyme activity in the liver and have a normal plasma Hcys levels by 2 folds higher than that in wild type littermates $[19,25]$. Thus, the $\mathrm{Cbs}^{+/-}$mice may develop mild 
A
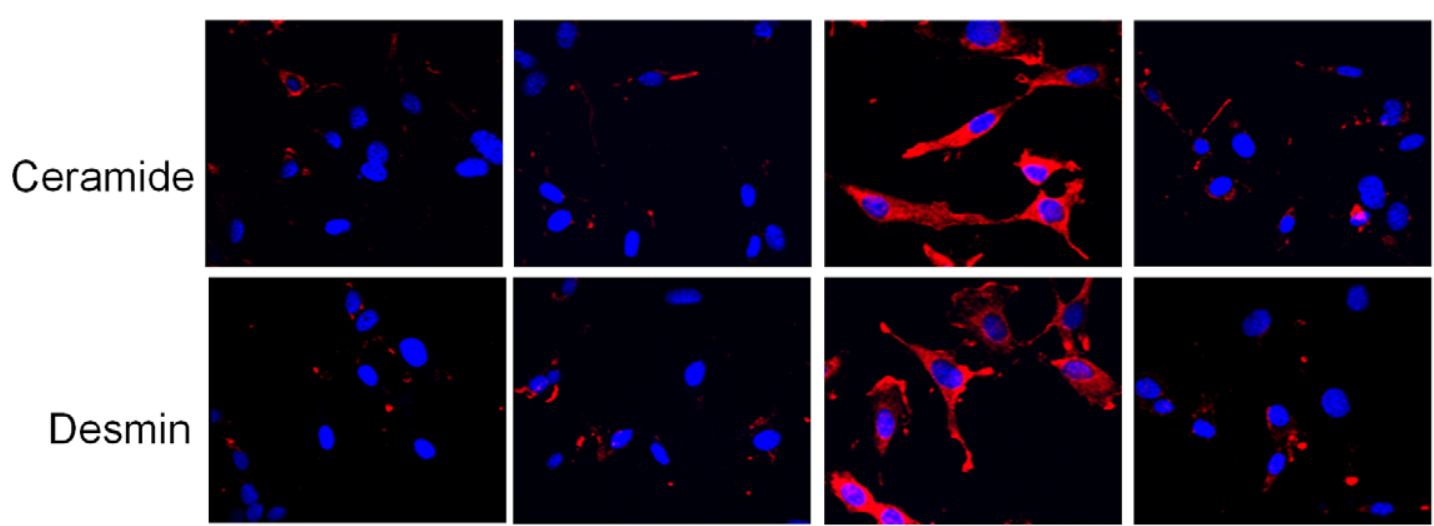

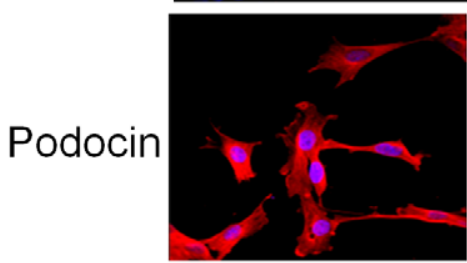

Ctrl

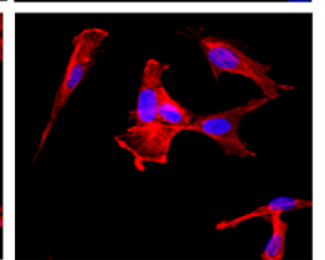

Ami

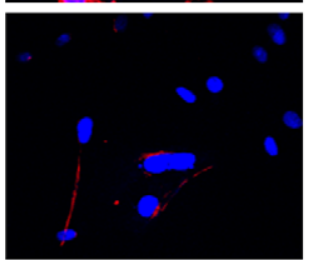

Ctrl

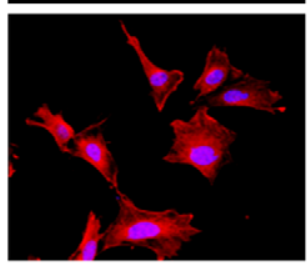

Ami

\section{Vehicle}

Hcy $(40 \mu \mathrm{M})$

B

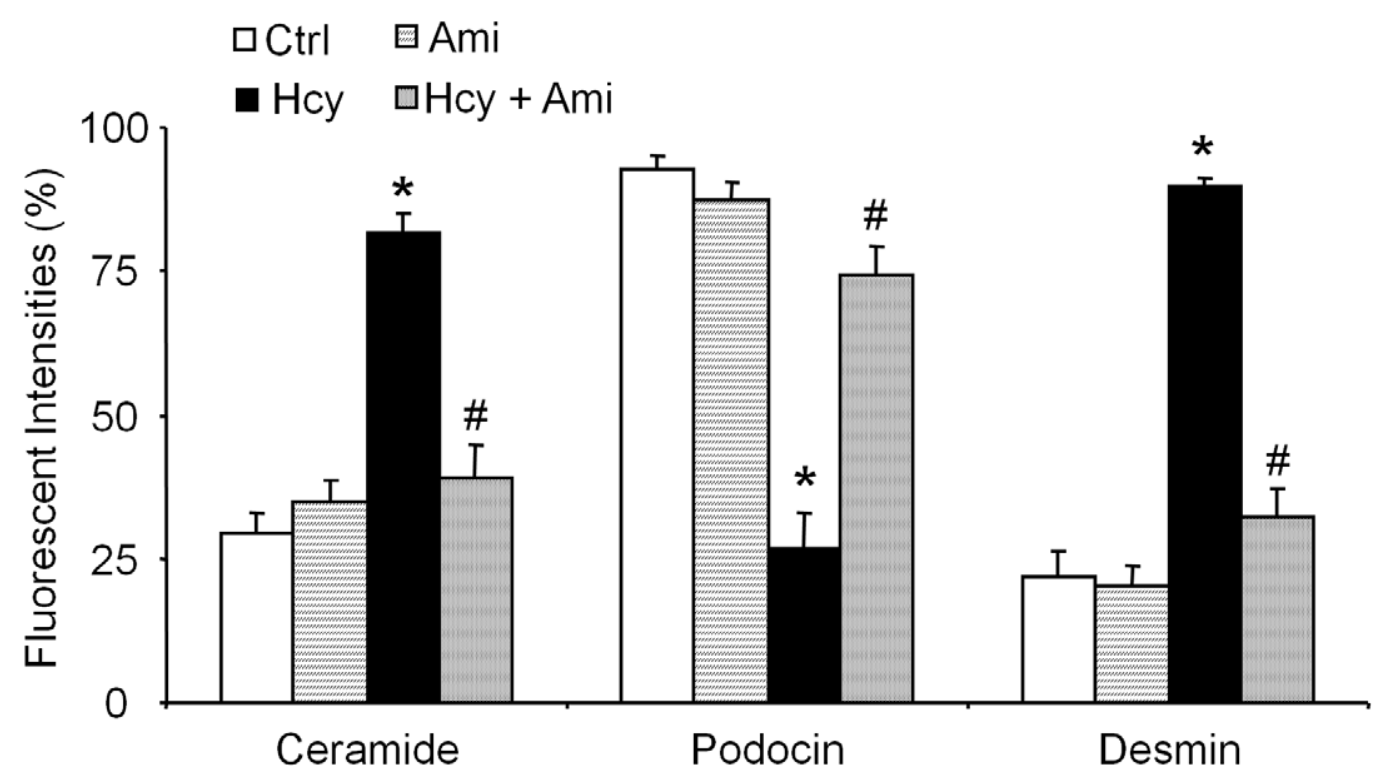

Figure 6. Production of ceramide, podocin and desmin staining in podocytes with or without Hcys and/or amitriptyline treatment. Cultured podocytes were treated with or without Hcys for $24 \mathrm{~h}$. A: Typical fluorescent microscopic images of ceramide, podocin and desmin in Hcys and/or amitriptyline treated podocytes $(n=5$ /group, Original magnification, $\times 400)$. B: Values are arithmetic means $\pm S E(n=5$ each group) of summarized data showing the percentage of positive staining cells of ceramide, desmin and podocin vs. control group. Ctrl: Control, Hcy: Homocysteine, Ami: Amitriptyline. * Significant difference $(P<0.05)$ compared to the control group; \# Significant difference $(P<0.05)$ compared to the Hcys group.

doi:10.1371/journal.pone.0045020.g006

hHcys and are a good model to study the hHcys-related disease processes [19]. Indeed, our results showed that plasma Hcys concentration was two fold higher in all $\mathrm{Cbs}^{+/-} \mathrm{Asm}^{+/+}, \mathrm{Cbs}^{+/}$
${ }^{-/} \mathrm{Asm}^{+/-}$and $\mathrm{Cbs}^{+/-} \mathrm{Asm}^{-/-}$mice compared to their Cbs wild type littermates. These results suggest that Asm itself is not involved in the metabolism of Hcys. Importantly, we found that 
A

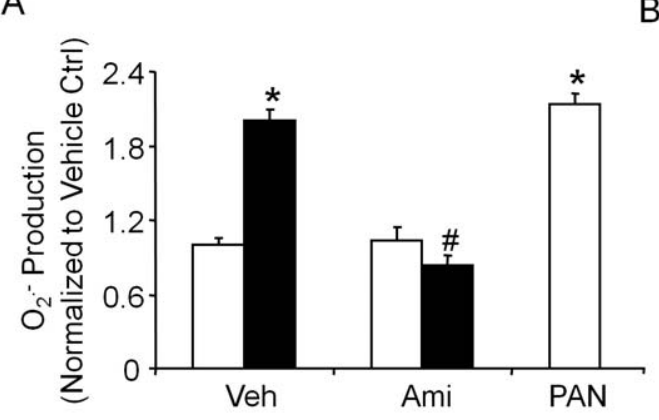

B

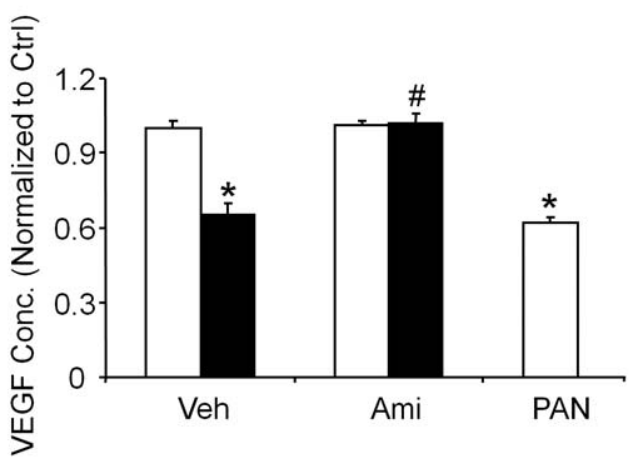

C

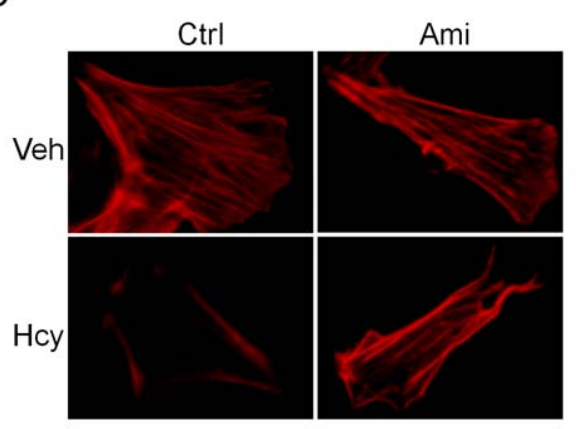

D

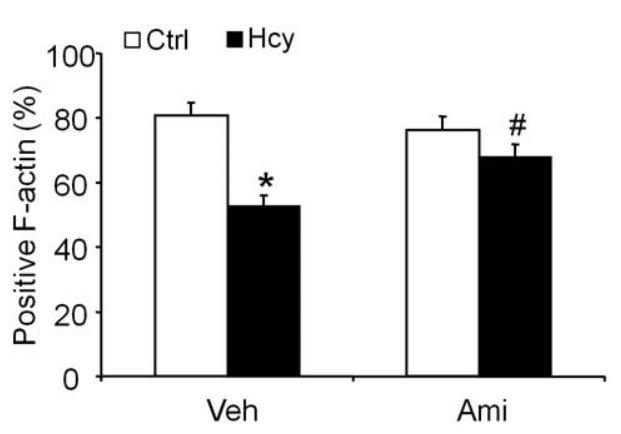

Figure 7. $\mathrm{O}_{2} \cdot{ }^{-}$production and VEGF levels in podocytes with or without Hcys and/or amitriptyline treatment. Cultured podocytes were treated with or without Hcys for $24 \mathrm{~h}$. Values are arithmetic means $\pm \mathrm{SE}\left(\mathrm{n}=5\right.$ each group) of $\mathrm{O}_{2}{ }^{-}$production (A), VEGF levels (B) in podocytes with or without Hcys and/or amitriptyline treatment. C. Representative microscopic images showing F-actin staining in podocytes using rhodaminephalloidin staining (magnification, $\times 400$ ). D. Summarized data showing the rate of podocytes retaining distinct longitudinal stress fibers. Scoring was from 100 podocytes on each slide in different groups ( $n=5$ each group). Ctrl: Control, Hcy: Homocysteine, Ami: Amitriptyline, Veh: Vehicle. * Significant difference $(P<0.05)$ compared to the control group; ${ }^{\#}$ Significant difference $(P<0.05)$ compared to the Hcys group. doi:10.1371/journal.pone.0045020.g007

the increased plasma Hcys concentration resulted in a remarkable glomerular damage or sclerosis in $\mathrm{Cbs}^{+/-} \mathrm{Asm}^{+/+}$mice, but not in $\mathrm{Cbs}^{+/-} \mathrm{Asm}^{-/-}$mice, suggesting that Asm gene knocking out prevents glomeruli from hHcys-induced injury in mice with fewer copies of Cbs genes.

There is considerable evidence supporting the critical role of ceramide signaling pathway in the pathogenesis of kidney diseases $[18,21]$. Ceramide production is mainly mediated via the hydrolysis of membrane sphingomyelin by various sphingomyelinases such as acid sphingomyelinase (Asm) or neutral sphingomyelinase (NSM) or by de novo synthesis via serine palmitoyltransferase (SPT) and ceramide synthase [26]. It is subsequently metabolized into sphingosine by ceramidases, and sphingosine can be further converted to S1P via sphingosine kinase [26] in response to a variety of stimuli including proinflammatory cytokines, oxidative stress, and increased levels of free fatty acids. It has been reported that ceramide may mediate the detrimental or pathogenic actions induced by many different injury factors in different cells and tissues [27-29]. More recently, ceramidemediated signaling has been found to cross talk with redox signaling associated with $\mathrm{NAD}(\mathrm{P}) \mathrm{H}$ oxidase, which represents a novel cellular signaling cascade that participates in the development of different diseases [18,21]. In this regard, we recently reported that increased plasma Hcys concentrations enhanced the ceramide production leading to activation of $\mathrm{NAD}(\mathrm{P}) \mathrm{H}$ oxidase in the kidney and that inhibition of ceramide production improved glomerular injury in those hyperhomocysteinemic rats [18]. The present study further demonstrated that Asm gene knockout attenuated hHcys-induced ceramide production, local oxidative stress and glomerular injury in mice lacking $\mathrm{Cbs}$ gene $\left(\mathrm{Cbs}^{+/}\right.$ $\left.{ }^{-\prime} \mathrm{Asm}^{-/-}\right)$.

Using podocin as a podocytes marker, our confocal microscopic data showed that hHcys-induced ceramide expression in glomeruli was mostly located in podocytes, as demonstrated by the colocalization of ceramide with podocin. This colocalization was substantially blocked in mice lacking both Asm and Cbs gene $\left(\mathrm{Cbs}^{+/-} \mathrm{Asm}^{-/-}\right)$. Furthermore, Asm activity in renal tissues were significantly increased in hyperhomocysteinemic $\mathrm{Cbs}^{+/-} \mathrm{Asm}^{+/+}$ mice, but not in $\mathrm{Cbs}^{+/-} \mathrm{Asm}^{-/-}$. The increased Asm activity in $\mathrm{Cbs}^{+/-} \mathrm{Asm}^{+/+}$mice may at least be partially due to the enhancement of Asm mRNA expression. In this regard, our previous studies have shown that hHcys increased the Asm activity and Asm mRNA expression in renal tissues of $\mathrm{Asm}^{+/+}$mice but not in $\mathrm{Asm}^{-1-}$ mice [21]. It was also shown that Hcys stimulation in podocytes enhanced the co-localization of membrane raft and Asm in the plasma membrane and revealed the translocation of Asm into cell membrane upon Hcys treatment [21]. These results suggest that hHcys-induced renal and glomerular ceramide production is mainly caused by activation of Asm in mice. In accordance with lowered ceramide production in $\mathrm{Cbs}^{+/-} \mathrm{Asm}^{-1-}$ mice, urinary albumin, protein excretion and glomerular injury and sclerosis were also significantly decreased compared with $\mathrm{Cbs}^{+/-/} \mathrm{Asm}^{+/+}$mice, suggesting that ceramide-associated renal injury during hHcys is alleviated in these $\mathrm{Cbs}^{+/-} \mathrm{Asm}^{-/-}$. Taken together, these results suggest that Asm gene knockout produces the beneficial effects in hyperhomocysteinemic mice that lack Cbs gene and therefore Asm gene and corresponding signaling 
pathway could be a therapeutic target for hHcys-induced podocyte injury and consequent glomerular sclerosis.

To further explore the mechanisms by which Asm gene knockout protects glomeruli from injury induced by hHcys, we observed more changes in podocyte function in various gene mutant mice. It has been well documented that proteinuria is a hallmark of renal injury and a major deteriorating factor for progression of end-stage renal diseases [30]. The outer aspect of glomerular basement membrane is lined up with very specialized visceral epithelial cells, named podocytes, and these podocytes serve as the final defense against urinary protein loss in the normal glomerulus [31]. Any damage to these podocytes and their slit diaphragm is intimately associated with proteinuria [32]. The assessment of normal slit diaphragm component such as podocin [33] and injured podocyte marker, desmin [34] are now therefore considered as two major sensitive markers of podocyte injury and subsequently glomerulopathy in renal diseases. In the present study, we showed that podocin and nephrin proteins were markedly decreased in hyperhomocysteinemic $\mathrm{Cbs}^{+/-} \mathrm{Asm}^{+/+}$ mice, but not in mice lacking both Asm and Cbs gene $\left(\mathrm{Cbs}^{+/}\right.$ $\left.{ }^{-} \mathrm{Asm}^{-1-}\right)$. In addition, we found that desmin was markedly increased in the glomeruli of $\mathrm{Cbs}^{+/-} \mathrm{Asm}^{+/+}$mice compared to $\mathrm{Cbs}^{+/-} \mathrm{Asm}^{-/-}$mice. These results further support the view that hHcys-induced glomerular injury is associated with increased ceramide production via Asm and its pathological action on podocytes. Furthermore, several studies have demonstrated that NADPH oxidase-dependent $\mathrm{O}_{2}$. ${ }^{-}$production is an early event for Hcys-induced glomerular cell damage and glomerular sclerosis $[18,35]$. It is possible that hHcys-induced NADPH oxidase activation is mediated by enhanced Asm activity in $\mathrm{Cbs}^{+/}$ ${ }^{-/} \mathrm{Asm}^{+/+}$mice. To test this hypothesis, the present study demonstrated by electron spin resonance analysis that hHcys indeed significantly increased NADPH oxidase-dependent $\mathrm{O}_{2}{ }^{-}$ production in $\mathrm{Cbs}^{+/-} \mathrm{Asm}^{+/+}$mice, but not in $\mathrm{Cbs}^{+/-} \mathrm{Asm}^{-/-}$ mice. These results support the view that Asm gene expression and ceramide production play a critical role in mediating glomerular $\mathrm{O}_{2}{ }^{-}{ }^{-}$production through activation of NADPH oxidase during hHcys.

In addition to the whole animal experiments, we also used cultured murine podocytes to examine the direct effect of altered ASM activity on ceramide production and podocyte injury, which attempted to further confirm the role of ceramide and consequent NADPH oxidase activation in Hcys-induced podocyte injury. It was found that Hcys stimulation in mouse podocytes significantly increased the ceramide and desmin expression, but decreased the podocin expression compared to control cell group. However, pretreatment with amitriptyline, an Asm inhibitor attenuated the Hcys-induced ceramide production and podocyte injury. Furthermore, we examined whether the effects of ASM inhibition are associated with Hcys-enhanced oxidative stress in podocytes. It was found that amitriptyline blocked Hcys-induced NADPH oxidase activation. Given that ceramide production is a critical early mechanism initiating or promoting Hcys-induced podocyte injury and glomerulosclerosis [36], these results from cultured mouse podocytes further confirm the findings from our in vivo studies, supporting a conclusion that Hcys-induced podocyte and glomerular injury is associated with increased ceramide production via ASM activity. Another functional abnormality of Hcys-induced podocyte injury was detected in the present study, namely, the production of VEGF-A in cultured podocytes. Podocyte-derived VEGF-A is found to be decreased in sclerotic glomeruli [37], while treatment with exogenous VEGF-A decreases renal sclerotic injuries and restores glomerular capillaries [38]. VEGF-A may serve as a crucial growth factor in maintaining the normal function of podocytes by preventing their apoptosis through the interaction with nephrin and activation of AKT signaling pathway [39]. In the present study, we found that Hcys treatment significantly decreased the production of VEGF-A in podocytes, which was restored by amitriptyline, an ASM inhibitor.

In summary, the present study demonstrated that mice lacking Asm gene produced beneficial effects on glomerular injury and sclerosis occurred in mice lacking Cbs gene with hHcys. This amelioration of glomerular injury by Asm gene knockout or ASM inhibition during hHcys suggests the pivotal role of Asm gene expression and ASM activation in hHcys-induced glomerulosclerosis. These findings may potentially direct towards the development of new therapeutic strategies for treatment and prevention of end-stage renal disease associated with hHcys and hHcys-related pathological processes such as hypertension, diabetes, atherosclerosis, and aging.

\section{Materials and Methods}

\section{Animals and Genotyping of Mice}

$\mathrm{Cbs}^{+/-}$and wild-type mice were purchased from the Jackson Laboratory. We first generated and characterized the mice lacking cystathionine $\beta$-synthase (Cbs) and Asm gene by cross breeding $\mathrm{Cbs}^{+/-}$and $\mathrm{Asm}^{+/-}$mice after each of original mouse strains was bred more than 5 generations with careful genotyping to maximize their purity (Figure 1A). Twelve weeks old male uninephrectomized $\mathrm{Cbs}^{+/+} / \mathrm{Asm}^{+/+}, \mathrm{Cbs}^{++} / \mathrm{Asm}^{+/-}, \mathrm{Cbs}^{+/+} / \mathrm{Asm}^{-/-}, \mathrm{Cbs}^{+/}$ ${ }^{-/} \mathrm{Asm}^{+/+} \mathrm{Cbs}^{+/-} \mathrm{Asm}^{+/-}, \mathrm{Cbs}^{+/-} \mathrm{Asm}^{-/-}$were used in the present study. In $\mathrm{Cbs}^{-1-}$ homozygous mice [40], a genomic fragment of exons 2 and 3, which encodes Cbs putative active site, was replaced by a neomycin selection cassette. PCR confirmation of this genotype was achieved by specific primers designed for wild-type extron 2, 5'-TCTGAGGACGAATGTTAGGATG-3' and 5'-CTAATGGAACTTCGCGTTGTG-3'. For confirmation of Asm gene deletion [41] in these mice, primers $5^{\prime}$ CTTGGGTGGAGAGGCTATTC- ${ }^{\prime}$ and 5'-AGGTGAGATGACAGGAGATC-3' were used for genotyping. The genomic DNA was extracted from the mouse tails using the ArchivePure DNA purification kit (5 Prime Inc., Gaithersburg, MD), and the PCR reaction was carried out in a Bio-Rad iCycler, initiated at $94^{\circ} \mathrm{C}$ for $1 \mathrm{~min}$ to denature the template and activate the $\mathrm{Taq}$ DNA polymerase, followed by 30 cycles of PCR amplification. Each cycle included denaturing at $94^{\circ} \mathrm{C}$ for $30 \mathrm{~s}$, annealing at $55^{\circ} \mathrm{C}$ for $30 \mathrm{~s}$, and extension at $72^{\circ} \mathrm{C}$ for $1 \mathrm{~min}$. The electrophoresis of PCR products was performed in $2 \%$ agarose gel. All protocols were approved by the Institutional Animal Care and Use Committee of the Virginia Commonwealth University.

\section{High-performance Liquid Chromatography (HPLC) Analysis}

Plasma Hcys levels were measured by HPLC method as we described previously [21,42]. A $100 \mu \mathrm{L}$ plasma or standard solution mixed with $10 \mu \mathrm{L}$ of internal standard, thionglycolic acid $(2.0 \mathrm{mmol} / \mathrm{L})$ solution, was treated with $10 \mu \mathrm{L}$ of $10 \%$ tri-nbutylphosphine (TBP) solution in dimethylformamide at $4{ }^{\circ} \mathrm{C}$ for 30 minutes. Then, $80 \mu \mathrm{L}$ of ice-cold $10 \%$ trichloro acetic acid (TCA) in $1 \mathrm{mmol} / \mathrm{L}$ EDTA was added and centrifuged to remove proteins in the sample. $100 \mu \mathrm{L}$ of the supernatant was transferred into the mixture of $20 \mu \mathrm{L}$ of $1.55 \mathrm{~mol} / \mathrm{L}$ sodium hydroxide, $250 \mu \mathrm{L}$ of $0.125 \mathrm{~mol} / \mathrm{L}$ borate buffer $(\mathrm{pH} 9.5)$, and $100 \mu \mathrm{L}$ of $1.0 \mathrm{mg} / \mathrm{mL}$ ABD-F solution. The resulting mixture was incubated at $60^{\circ} \mathrm{C}$ for 30 minutes to accomplish derivatization of thiols. HPLG was performed with a HP 1100 series instrument (Agilent Technologies, Waldbronn, Germany) equipped with a binary 
pump, a vacuum degasser, a thermo stated column compartment, and an auto sampler (Agilent Technologies, Waldbronn, Germany). Separation was carried out at an ambient temperature on an analytical column, Supelco LC-18-DB (Supelco; $150 \times 4.6 \mathrm{~mm}$ i.d., $5 \mu \mathrm{m}$ particle size) with a Supelcosil LC-18 guard column (Supelco; $20 \times 4.6 \mathrm{~mm}$ i.d., $5 \mu \mathrm{m}$ particle size). Fluorescence intensities were measured with an excitation wavelength of $385 \mathrm{~nm}$ and emission wavelength of $515 \mathrm{~nm}$ by a HewlettPackard Model 1046A fluorescence detector (Agilent Technologies). The peak area of the chromatographs was quantified with a Hewlett-Packard 3392 integrator (Agilent Technologies). The analytical column was eluted with $0.1 \mathrm{~mol} / \mathrm{L}$ potassium dihydrogen phosphate buffer $(\mathrm{pH} 2.1)$ containing $6 \%$ acetonitrile (v/v) as the mobile phase with a flow rate of $2.0 \mathrm{~mL} / \mathrm{min}$.

\section{Morphological Examinations}

The fixed kidneys were paraffin-embedded, and sections were prepared and stained with Periodic acid-Schiff stain. Glomerular damage index (GDI) was calculated from 0 to 4 on the basis of the degree of glomerulosclerosis and mesangial matrix expansion as described previously [43]. In general, we counted 50 glomeruli in total in each kidney slide under microscope, when each glomerulus was graded level 0-4 damages. 0 represents no lesion, 1+ represents sclerosis of $<25 \%$ of the glomerulus, while $2+, 3+$, and $4+$ represent sclerosis of $25 \%$ to $50 \%,>50 \%$ to $75 \%$, and $>75 \%$ of the glomerulus. A whole kidney average sclerosis index was obtained by averaging scores from counted glomeruli [44]. This observation was conducted by two independent investigators who were blinded to the treatment of experimental animal groups.

\section{Asm Activity}

The activity of Asm was determined as we described previously [13,21]. Briefly, $\mathcal{N}$-methyl- $\left[{ }^{14} \mathrm{C}\right]$-sphingomyelin was incubated with renal cortical tissue homogenates, and the metabolites of sphingomyelin, $\left[{ }^{14} \mathrm{C}\right]$-choline phosphate was quantified. An aliquot of homogenates $(20 \mu \mathrm{g})$ was mixed with $0.02 \mu \mathrm{Ci}$ of $\mathcal{N}$ methyl ${ }^{14} \mathrm{C}$-sphingomyelin in $100 \mu \mathrm{l}$ acidic reaction buffer containing $100 \mathrm{mmol} / \mathrm{L}$ sodium acetate, and $0.1 \%$ Triton $\mathrm{X}$ $100, \mathrm{pH} 5.0$, and incubated at $37^{\circ} \mathrm{C}$ for $15 \mathrm{~min}$. The reaction was terminated by adding $1.5 \mathrm{ml}$ chloroform:methanol (2:1) and $0.2 \mathrm{ml}$ double-distilled water. The samples were then vortexed and centrifuged at 1,000 $g$ for $5 \mathrm{~min}$ to separate into two phases. A portion of the upper aqueous phase containing ${ }^{14} \mathrm{C}$-choline phosphate was transferred to scintillation vials and counted in a Beckman liquid scintillation counter. The choline phosphate formation rate $\left(\mathrm{nmol} \cdot \mathrm{min}^{-1} \cdot \mathrm{mg}\right.$ protein $\left.{ }^{-1}\right)$ was calculated to represent the enzyme activity.

\section{Liquid Chromatography-electrospray lonization Tandem Mass Spectrometry (LC-ESI-MS) for Quantitation of Ceramide}

Separation, identification and quantitation of ceramide in plasma were performed by LC/MS. The HPLC equipped with a binary pump, a vacuum degasser, a thermostated column compartment and an autosampler (Waters, Milford, MA, USA). The HPLC separations were performed at $70^{\circ} \mathrm{C}$ on a RP C18 Nucleosil AB column (5 $\mathrm{m}, 70 \mathrm{~mm} \times 2 \mathrm{~mm}$ i.d.) from Macherey Nagel (Duren, Germany). The mobile phase was a gradient mixture formed as described [45]. The renal lipids were extracted according to previous studies. To avoid any loss of lipids, the whole procedure was performed in siliconized glassware. MS detection was carried out using a Quattro II quadrupole mass spectrometer (Micromass, Altrincham, England) operating under
MassLynx 3.5 and configured with a Z-spray electrospray ionization source. Source conditions were same as described previously in our studies and by others $[21,45]$.

\section{Cell Culture}

Conditionally immortalized mouse podocyte cell line [46], kindly provided by Dr. Klotman PE (Division of Nephrology, Department of Medicine, Mount Sinai School of Medicine, New York, NY, USA), was cultured on collagen I-coated flasks or plates in RPMI 1640 medium supplemented with recombinant mouse interferon $-\gamma$ at $33^{\circ} \mathrm{C}$. After differentiated at $37^{\circ} \mathrm{C}$ for $10-14$ days without interferon $-\gamma$, podocytes were used for the proposed experiments as we described previously [21].

\section{Indirect Immuno-fluorescent Staining}

Podocytes were grown on poly-L-lysine-coated chambers and treated with Hcys $(40 \mu \mathrm{M}, 24 \mathrm{hrs})$. In additional group of cells, the Asm inhibitor, amitriptyline (20 $\mu \mathrm{M}$, Sigma, St. Louis, MO, USA) was added to pretreat the cells for 30 minutes before the addition of Hcys. The cells were fixed in 4\% PFA for 15 minutes. After rinsed with phosphate-buffer saline (PBS), cells were incubated with anti-podocin (Sigma, St. Louis, MO, USA, 1: 100), antidesmin (BD Biosciences, San Jose, CA, 1: 100), or anti-ceramide (Enzo Life Sciences, Plymouth Meeting, PA, 1:200) antibodies. After washing, the slides were incubated with Alexa 555-labeled secondary antibodies for $1 \mathrm{~h}$ at room temperature. After being mounted with DAPI-containing mounting solution, the slides were observed under a fluorescence microscope and photos were taken and analyzed. The fluorescent intensities were quantified by the Image Pro Plus 6.0 software (Media Cybernetics, Bethesda, MD, USA) and the data was normalized to control cells.

\section{Western Blot Analysis}

Western blot analysis was performed as we described previously [36]. In brief, proteins from the mouse renal cortex were extracted using sucrose buffer containing protease inhibitor. After boiled for $5 \mathrm{~min}$ at $95^{\circ} \mathrm{C}$ in a $5 \times$ loading buffer, $20 \mu \mathrm{g}$ of total proteins were subjected to SDS-PAGE, transferred onto a PVDF membrane and blocked. Then, the membrane was probed with primary antibody of anti-desmin (1:500, BD Biosciences, San Jose, CA, USA) or anti- $\beta$-actin (1:3000, Santa Cruz Biotechnology, Santa Cruz, CA, USA) overnight at $4^{\circ} \mathrm{C}$ followed by incubation with horseradish peroxidase-labeled IgG (1:5000). The immuno-reactive bands were detected by chemiluminescence methods and visualized on Kodak Omat X-ray films. Densitometric analysis of the images obtained from X-ray films was performed using the Image $\mathrm{J}$ software (NIH, Bethesda, MD, USA).

\section{Direct Fluorescent Staining of F-actin}

To determine the role of ASM inhibition in Hcys-induced cytoskeleton changes, podocytes were cultured in 8-well chambers and treated with Hcys $(40 \mu \mathrm{M}, 24 \mathrm{hrs})$. In additional group of cells, the Asm inhibitor, amitriptyline ( $20 \mu \mathrm{M}$, Sigma, St. Louis, MO, USA), was added to pretreat the cells for 30 minutes before the addition of Hcys or puromycin aminonucleoside (PAN, $100 \mu \mathrm{g} / \mathrm{ml}$, Sigma, St. Louis, MO, USA) for $24 \mathrm{~h}$. After pretreatment with vehicle, amitriptyline, the cells were treated with L-Hcys $(40 \mu \mathrm{M})$ for $24 \mathrm{~h}$. After washing with PBS, the cells were fixed in $4 \%$ paraformaldehyde for $15 \mathrm{~min}$ at room temperature, permeabilized with $0.1 \%$ Triton X-100, and blocked with $3 \%$ bovine serum albumin. F-actin was stained with rhodamine-phalloidin (Invitrogen, Carlsbad, CA, USA) for $15 \mathrm{~min}$ at room temperature. After mounting, the slides were 
examined by a confocal laser scanning microscope. Cells with distinct F-actin fibers were counted as we described previously [36]. Scoring was obtained from 100 podocytes on each slide in different groups.

\section{ELISA for Vascular Endothelial Growth Factor A (VEGF-A) in Podocytes}

After pretreatment with amitriptyline $(20 \mu \mathrm{M}$, Sigma, St. Louis, MO, USA), and its vehicle, podocytes were incubated with Hcys $(40 \mu \mathrm{M})$ for $24 \mathrm{~h}$. A specific podocyte injury compound, puromycin aminonucleoside (PAN, $100 \mu \mathrm{g} / \mathrm{ml}$ ) was used to treat cells for $24 \mathrm{~h}$ to serve as a positive control. The supernatant was collected for ELISA assay of VEGF-A using a commercially available kit (R\&D system, Minneapolis, MN).

\section{Urinary Total Protein and Albumin Excretion Measurements}

The 24-hour urine samples were collected using metabolic cages and subjected to total protein and albumin excretion measurements, respectively $[13,21]$. Total protein content in the urine was detected by Bradford method using a UV spectrophotometer. Urine albumin was detected using a commercially available albumin ELISA kit (Bethyl Laboratories, Montgomery, TX).

\section{Electronic Spin Resonance (ESR) Analysis of $\mathrm{O}_{2}$. Production}

For detection of Nox-dependent $\mathrm{O}_{2}{ }^{-}$production, proteins from the renal cortex and cultured podocytes were extracted using sucrose buffer and resuspended with modified Kreb's-Hepes buffer containing deferoximine $(100 \mathrm{mM}$, Sigma) and diethyldithiocarbamate ( $5 \mathrm{mM}$, Sigma). The NADPH oxidase-dependent $\mathrm{O}_{2}$. production was examined by addition of $1 \mathrm{mM} \mathrm{NADPH}$ as a substrate in $50 \mathrm{mg}$ protein and incubated for $15 \mathrm{~min}$ at $37^{\circ} \mathrm{C}$ in the presence or absence of SOD $(200 \mathrm{U} / \mathrm{ml})$, and then supplied with $1 \mathrm{mM} \mathrm{O}_{2}$. ${ }^{-}$specific spin trapping substance, 1-hydroxy-3methoxycarbonyl-2,2,5,5-tetramethylpyrrolidine (CMH, Noxygen, Elzach, Germany). The mixture was loaded in glass capillaries and immediately analyzed for $\mathrm{O}_{2} \cdot{ }^{-}$production kinetically for $10 \mathrm{~min}$ in a Miniscope MS200 electromagnetic spin resonance (ESR) spectrometer (Magnettech Ltd, Berlin, Germany). The ESR settings were as follows: biofield, 3350; field sweep, $60 \mathrm{G}$; microwave frequency, $9.78 \mathrm{GHz}$; microwave power, $20 \mathrm{~mW}$; modulation amplitude, $3 \mathrm{G}$; 4,096 points of resolution; receiver gain, 20 for tissue and 50 for cells. The results were expressed as the fold changes of control.

\section{References}

1. Smith EL, Schuchman EH (2008) The unexpected role of acid sphingomyelinase in cell death and the pathophysiology of common diseases. FASEB J 22: 3419 3431 .

2. Kornhuber J, Muehlbacher M, Trapp S, Pechmann S, Friedl A, et al. (2011) Identification of novel functional inhibitors of acid sphingomyelinase. Plos One 6: e23852.

3. Lee H, Rotolo JA, Mesicek J, Penate-Medina T, Rimner A, et al. (2011) Mitochondrial ceramide-rich macrodomains functionalize Bax upon irradiation. Plos One 6: e19783.

4. Garcia-Barros M, Paris F, Cordon-Cardo C, Lyden D, Rafii S, et al. (2003) Tumor response to radiotherapy regulated by endothelial cell apoptosis. Science 300: 1155-1159

5. Grassme H, Cremesti A, Kolesnick R, Gulbins E (2003) Ceramide-mediated clustering is required for CD95-DISC formation. Oncogene 22: 5457-5470.

6. Yu ZF, Nikolova-Karakashian M, Zhou D, Cheng G, Schuchman EH, et al. (2000) Pivotal role for acidic sphingomyelinase in cerebral ischemia-induced ceramide and cytokine production, and neuronal apoptosis. J Mol Neurosci 15: 85-97.

\section{Double-immunofluorescent Staining}

Double-immunofluorescent staining was performed using frozen slides from mouse kidneys. After fixation, the slides were incubated with rabbit anti-podocin antibody at 1:100 (Sigma, St. Louis, MO, USA), which was followed by incubation with Alexa 488-labeled goat anti-rabbit secondary antibody. Then, mouse anti-ceramide antibody (Enzo Life Sciences, Plymouth Meeting, PA, 1:50) was used to incubate with the slides overnight at $4^{\circ} \mathrm{C}$. After washing, the slides were incubated with corresponding Alexa 555-labeled secondary antibodies. Finally, the slides were mounted and subjected to examinations using a confocal laser scanning microscope (Fluoview FV1000, Olympus, Japan). All exposure settings were kept constant for each group of kidneys.

\section{Immunofluorescent Staining}

Immunofluorescent staining was performed using frozen slides of mouse kidneys. After fixation with acetone, the slides were incubated with anti-podocin (Sigma, St. Louis, MO, USA, 1:100), anti-desmin (BD Biosciences, San Jose, CA, 1:50), anti-nephrin (Abcam, Cambridge, MA, 1:50), antibodies overnight at $4^{\circ} \mathrm{C}$. Then, these slides were washed and incubated with corresponding Texas Red-labeled secondary antibodies. Finally, the slides were washed, mounted and subjected to fluorescent microscopic examination. The images were captured with a spot CCD camera and a pseudocolor was added to corresponding fluorescent image (Diagnostic Instruments Inc., Sterlin Heights, MI, USA). All exposure settings were kept constant for each group of kidneys.

\section{Statistical Analysis}

Data are provided as arithmetic means \pm SEM; $n$ represents the number of independent experiments. All data were tested for significance using ANOVA for data obtained from multiple animal or experimental groups or paired and unpaired Student's ttest for two groups of animals or experimental protocols. The glomerular damage index was analysed for statistic significance using a nonparametric Mann-Whitney rank sum test. Only results with $\mathrm{p}<0.05$ were considered statistically significant.

\section{Author Contributions}

Conceived and designed the experiments: KMB PL. Performed the experiments: KMB M. Xia JMA M. Xu CL. Analyzed the data: KMB M. Xia JMA M. Xu CL. Wrote the paper: KMB PL.

7. Paris F, Fuks Z, Kang A, Capodieci P, Juan G, et al. (2001) Endothelial apoptosis as the primary lesion initiating intestinal radiation damage in mice. Science 293: 293-297.

8. Dimanche-Boitrel MT, Meurette O, Rebillard A, Lacour S (2005) Role of early plasma membrane events in chemotherapy-induced cell death. Drug Resist Updat 8: 5-14.

9. Garcia-Ruiz C, Colell A, Mari M, Morales A, Calvo M, et al. (2003) Defective TNF-alpha-mediated hepatocellular apoptosis and liver damage in acidic sphingomyelinase knockout mice. J Clin Invest 111: 197-208.

10. Dhami R, He X, Schuchman EH (2010) Acid sphingomyelinase deficiency attenuates bleomycin-induced lung inflammation and fibrosis in mice. Cell Physiol Biochem 26: 749-760.

11. Teichgraber V, Ulrich M, Endlich N, Riethmuller J, Wilker B, et al. (2008) Ceramide accumulation mediates inflammation, cell death and infection susceptibility in cystic fibrosis. Nat Med 14: 382-391.

12. Becker KA, Riethmuller J, Luth A, Doring G, Kleuser B, et al. (2010) Acid sphingomyelinase inhibitors normalize pulmonary ceramide and inflammation in cystic fibrosis. Am J Respir Cell Mol Biol 42: 716-724. 
13. Boini KM, Zhang C, Xia M, Poklis JL, Li PL (2010) Role of sphingolipid mediator ceramide in obesity and renal injury in mice fed a high-fat diet. J Pharmacol Exp Ther 334: 839-846.

14. Moles A, Tarrats N, Morales A, Dominguez M, Bataller R, et al. (2010) Acidic sphingomyelinase controls hepatic stellate cell activation and in vivo liver fibrogenesis. Am J Pathol 177: 1214-1224.

15. Achar E, Maciel TT, Collares CF, Teixeira VP, Schor N (2009) Amitriptyline attenuates interstitial inflammation and ameliorates the progression of renal fibrosis. Kidney Int 75: 596-604.

16. Yi F, Xia M, Li N, Zhang C, Tang L, et al. (2009) Contribution of guanine nucleotide exchange factor Vav2 to hyperhomocysteinemic glomerulosclerosis in rats. Hypertension 53: 90-96.

17. Ingram AJ, Krepinsky JC, James L, Austin RG, Tang D, et al. (2004) Activation of mesangial cell MAPK in response to homocysteine. Kidney Int 66: 733-745.

18. Yi F, Zhang AY, Li N, Muh RW, Fillet M, et al. (2006) Inhibition of ceramideredox signaling pathway blocks glomerular injury in hyperhomocysteinemic rats. Kidney Int 70: 88-96.

19. Sen U, Basu P, Abe OA, Givvimani S, Tyagi N, et al. (2009) Hydrogen sulfide ameliorates hyperhomocysteinemia-associated chronic renal failure. Am J Physiol Renal Physiol 297: F410-419.

20. Sen U, Givvimani S, Abe OA, Lederer ED, Tyagi SC (2011) Cystathionine betasynthase and cystathionine gamma-lyase double gene transfer ameliorate homocysteine-mediated mesangial inflammation through hydrogen sulfide generation. Am J Physiol Cell Physiol 300: C155-163.

21. Boini KM, Xia M, Li C, Zhang C, Payne LP, et al. (2011) Acid sphingomyelinase gene deficiency ameliorates the hyperhomocysteinemiainduced glomerular injury in mice. Am J Pathol 179: 2210-2219.

22. Ernest S, Hosack A, O'Brien WE, Rosenblatt DS, Nadeau JH (2005) Homocysteine levels in $\mathrm{A} / \mathrm{J}$ and $\mathrm{C} 57 \mathrm{BL} / 6 \mathrm{~J}$ mice: genetic, diet, gender, and parental effects. Physiol Genomics 21: $404-410$.

23. Wald DS, Law M, Morris JK (2002) Homocysteine and cardiovascular disease: evidence on causality from a meta-analysis. BMJ 325: 1202

24. Carnicer R, Guzman MA, Acin S, Surra JC, Navarro MA, et al. (2008) Genetic background in apolipoprotein A-I and cystathionine beta-synthase deficiency. Front Biosci 13: 5155-5162.

25. Robert K, Chasse JF, Santiard-Baron D, Vayssettes C, Chabli A, et al. (2003) Altered gene expression in liver from a murine model of hyperhomocysteinemia. J Biol Chem 278: 31504-31511.

26. Futerman AH, Hannun YA (2004) The complex life of simple sphingolipids. EMBO Rep 5: 777-782.

27. Ueda N, Kaushal GP, Shah SV (2000) Apoptotic mechanisms in acute renal failure. Am J Med 108: 403-415.

28. van der Wouden EA, Sandovici M, Henning RH, de Zeeuw D, Deelman LE (2004) Approaches and methods in gene therapy for kidney disease. J Pharmacol Toxicol Methods 50: 13-24.

29. Williams KJ, Tabas I (1995) The response-to-retention hypothesis of early atherogenesis. Arterioscler Thromb Vasc Biol 15: 551-561.

30. Remuzzi G, Bertani T (1998) Pathophysiology of progressive nephropathies. N Engl J Med 339: 1448-1456.
31. Nagase M, Shibata S, Yoshida S, Nagase T, Gotoda T, et al. (2006) Podocyte injury underlies the glomerulopathy of Dahl salt-hypertensive rats and is reversed by aldosterone blocker. Hypertension 47: 1084-1093.

32. Pavenstadt H, Kriz W, Kretzler M (2003) Cell biology of the glomerular podocyte. Physiol Rev 83: 253-307.

33. Kawachi H, Koike H, Kurihara H, Yaoita E, Orikasa M, et al. (2000) Cloning of rat nephrin: expression in developing glomeruli and in proteinuric states. Kidney Int 57: 1949-1961.

34. Floege J, Kriz W, Schulze M, Susani M, Kerjaschki D, et al. (1995) Basic fibroblast growth factor augments podocyte injury and induces glomerulosclerosis in rats with experimental membranous nephropathy. J Clin Invest 96: 2809-2819.

35. Yi F, Zhang AY, Janscha JL, Li PL, Zou AP (2004) Homocysteine activates NADH/NADPH oxidase through ceramide-stimulated Rac GTPase activity in rat mesangial cells. Kidney Int 66: 1977-1987.

36. Zhang C, Hu JJ, Xia M, Boini KM, Brimson C, et al. (2010) Redox signaling via lipid raft clustering in homocysteine-induced injury of podocytes. Biochim Biophys Acta 1803: 482-491.

37. Yuan HT, Li XZ, Pitera JE, Long DA, Woolf AS (2003) Peritubular capillary loss after mouse acute nephrotoxicity correlates with down-regulation of vascular endothelial growth factor-A and hypoxia-inducible factor-1 alpha. Am J Pathol 163: 2289-2301

38. Kang DH, Johnson RJ (2003) Vascular endothelial growth factor: a new player in the pathogenesis of renal fibrosis. Curr Opin Nephrol Hypertens 12: 43-49.

39. Foster RR, Saleem MA, Mathieson PW, Bates DO, Harper SJ (2005) Vascular endothelial growth factor and nephrin interact and reduce apoptosis in human podocytes. Am J Physiol Renal Physiol 288: F48-57.

40. Watanabe M, Osada J, Aratani Y, Kluckman K, Reddick R, et al. (1995) Mice deficient in cystathionine beta-synthase: animal models for mild and severe homocyst(e)inemia. Proc Natl Acad Sci U S A. 92: 1585-1589.

41. Horinouchi K, Erlich S, Perl DP, Ferlinz K, Bisgaier CL, et al. (1995) Acid sphingomyelinase deficient mice: a model of types A and B Niemann-Pick disease. Nat Genet 10: 288-293.

42. Chen YF, Li PL, Zou AP (2002) Effect of hyperhomocysteinemia on plasma or tissue adenosine levels and renal function. Circulation 106: 1275-1281.

43. Raij L, Azar S, Keane W (1984) Mesangial immune injury, hypertension, and progressive glomerular damage in Dahl rats. Kidney Int 26: 137-143.

44. Zhang C, Hu JJ, Xia M, Boini KM, Brimson CA, et al. (2010) Protection of podocytes from hyperhomocysteinemia-induced injury by deletion of the gp91phox gene. Free Radic Biol Med 48: 1109-1117.

45. Fillet M, Van Heugen JC, Servais AC, De Graeve J, Crommen J (2002) Separation, identification and quantitation of ceramides in human cancer cells by liquid chromatography-electrospray ionization tandem mass spectrometry. J Chromatogr A 949: 225-233.

46. Husain M, Gusella GL, Klotman ME, Gelman IH, Ross MD, et al. (2002) HIV1 Nef induces proliferation and anchorage-independent growth in podocytes. J Am Soc Nephrol 13: 1806-1815. 